\title{
Tumour-induced osteomalacia
}

\author{
Anjali A Bhatt, Suma S Mathews, Anusha Kumari, Thomas V Paul * \\ Hong Kong Med J 2014;20:350.e1-2 \\ DOI: 10.12809/hkmj133981
}

Tumour-induced osteomalacia (also known as oncogenic osteomalacia) is an uncommon condition. The fibroblast growth factor 23 (FGF-23), a polypeptide secreted by mesenchymal tumours, causes phosphaturia, which in turn results in defective mineralisation. In addition, FGF-23 causes suppression of the enzyme $1 \alpha$-hydroxylase located in the proximal convoluted tubules of kidneys and responsible for final activation of vitamin D (from 25-hydroxyvitamin D to 1,25-dihydroxyvitamin D). ${ }^{1}$ Once the tumour causing the osteomalacia is found, its excision usually results in complete remission of the bone disorder. ${ }^{2}$ Herein we report on a patient who presented to us with the features of oncogenic osteomalacia.

A 32-year-old woman born of nonconsanguineous parents complained of gradually increasing proximal muscle weakness of both lower limbs over 1 year in February 2012. She also had pain in both hips while walking, which restricted her daily activities. She had no history of any chronic gastrointestinal illness, and was not taking medication which might affect bone metabolism. Nor was there a family history of any similar illness. Clinical examination revealed severe proximal muscle weakness in both lower limbs. Active movements like external rotation and abduction at the both hips were painful. Otherwise the examination was unremarkable.

Biochemical evaluation revealed hypophosphataemia with phosphaturia (Table). Radiology of the hips showed bilateral femoral neck pseudo-

TABLE. Biochemical parameters

\begin{tabular}{lcc}
\hline Variable & Value & Reference range \\
\hline Serum calcium $(\mathrm{mmol} / \mathrm{L})$ & 2.29 & $2.10-2.55$ \\
Serum creatinine $(\mu \mathrm{mol} / \mathrm{L})$ & 80 & $46-92$ \\
Serum phosphate $(\mathrm{mmol} / \mathrm{L})$ & 0.45 & $0.80-1.45$ \\
Serum alkaline phosphatase $(\mathrm{U} / \mathrm{L})$ & 105 & $40-125$ \\
Serum 25(OH) vitamin-D $(\mathrm{ng} / \mathrm{mL})$ & 56 & $30-75$ \\
Serum parathyroid hormone $(\mathrm{pg} / \mathrm{mL})$ & 58 & $8-74$ \\
Serum electrolyte $(\mathrm{mmol})$ & & \\
$\quad$ Potassium & 4.2 & $3.5-5.0$ \\
$\quad$ Bicarbonate & 24 & $22-29$ \\
$\quad$ Chloride & 108 & $95-105$ \\
Serum albumin $(\mathrm{g} / \mathrm{L})$ & 49 & $35-50$ \\
Plasma FGF-23 $(\mathrm{RU} / \mathrm{mL})$ & $>2500$ & $10-96$ \\
\hline Abbrion $\mathrm{FGF}-23=\mathrm{fb}$ &
\end{tabular}

Abbreviation: FGF-23 = fibroblast growth factor 23 fractures (Fig 1). These abnormalities favoured a diagnosis of hypophosphataemic osteomalacia. Further workup yielded a high FGF-23 level and computed tomography of the paranasal sinuses showed a soft tissue tumour in the left ethmoidal sinus (Fig 2).

The patient was treated with phosphate supplements and underwent complete excision of the left ethmoidal sinus mass. Histopathological examination confirmed the diagnosis of a

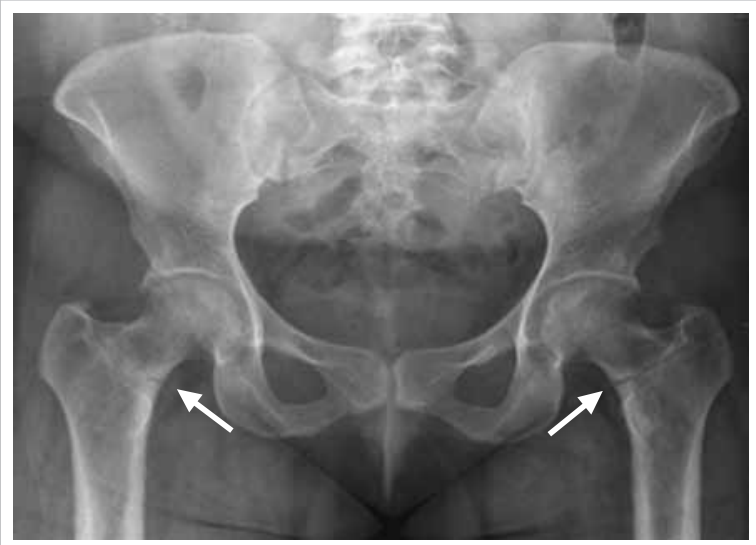

FIG I. Pseudofractures seen in both femoral neck (arrows)

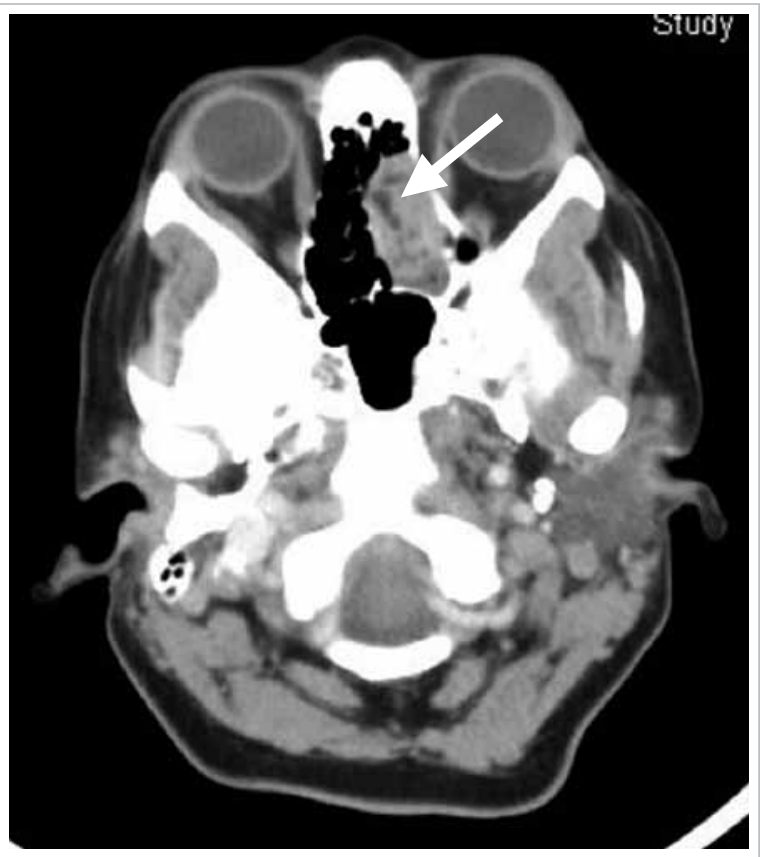

FIG 2. Heterogeneously enhancing soft tissue lesion in left posterior ethmoid sinus (arrow) 


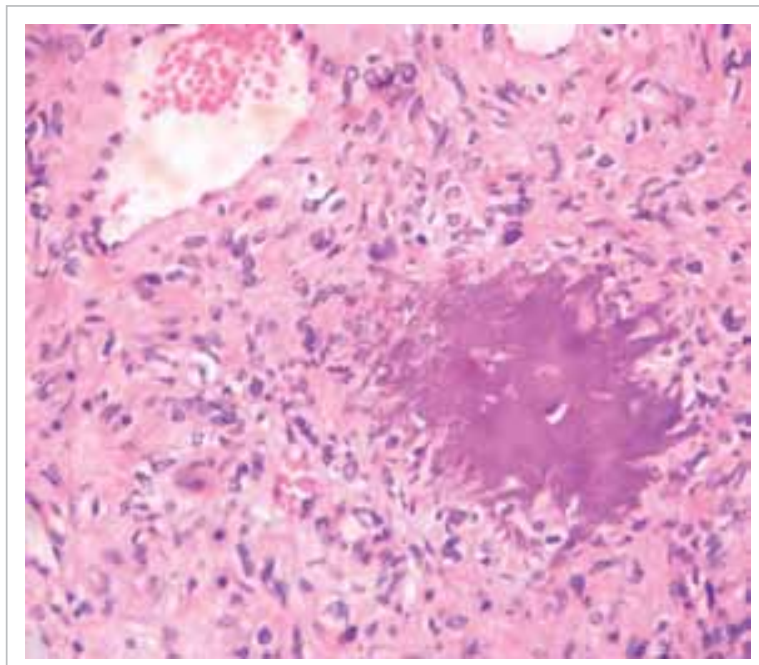

FIG 3. High-power view showing distinctive grungy pattern of matrix calcification with surrounding bland small roundto-spindle cells (H\&E; original magnification, $x 40$ ) embedded in a vascular to myxochondroid matrix with variable amounts of mature adipose tissue (Fig 3). This matrix calcifies in an unusual 'grungy' fashion, inciting an osteoclast-rich and fibrohistiocytic response. A very prominent feature of PMT-MCT is its elaborate intrinsic microvasculature. Malignant PMT-MCTs resemble undifferentiated pleomorphic sarcomas or fibrosarcomas. ${ }^{3}$ After complete excision of the tumour, most patients improve dramatically ${ }^{4}$ and become symptomatically, biochemically, and radiologically better. Such results should prompt the physicians to search for such treatable and potentially curable causes, whenever they encounter hypophosphataemic osteomalacia.

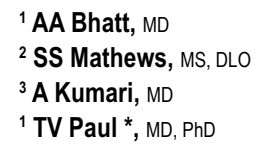

Departments of ${ }^{1}$ Endocrinology, Diabetes and Metabolism, ${ }^{2} E N T$, and ${ }^{3}$ General Pathology, Christian Medical College, Vellore 632 004, India

* Corresponding author: thomasvpaul@yahoo.com

phosphaturic mesenchymal tumour. The patient remained stable after surgery. Two months later she was asymptomatic, by which time her muscle weakness had resolved markedly. Respective serial serum phosphate concentrations were $0.90,1.00$, and $1.35 \mathrm{mmol} / \mathrm{L}$ at 1,2 and 4 weeks after surgery. After surgery, her plasma FGF-23 levels were undetectable.

Phosphaturic mesenchymal tumours are rare mesenchymal tumours and mostly comprised of a single histological entity with mixed connective tissue (designated PMT-MCT). Such tumours can occur in the soft tissue or bone. ${ }^{3}$ Most PMT-MCTs are histologically and clinically benign with rare instances of malignancy. Microscopically, PMTMCTs are variable in appearance, usually being composed of small, bland round-to-spindle cells

\section{References}

1. Chokyu I, Ishibashi K, Goto T, Ohata K. Oncogenic osteomalacia associated with mesenchymal tumor in the middle cranial fossa: a case report. J Med Case Rep 2012;6:181.

2. Komínek P, Stárek I, Geierová M, Matoušek P, Zeleník K. Phosphaturic mesenchymal tumour of the sinonasal area: case report and review of the literature. Head Neck Oncol 2011;3:16

3. Folpe AL, Fanburg-Smith JC, Billings SD, et al. Most osteomalacia-associated mesenchymal tumors are a single histopathologic entity: an analysis of 32 cases and a comprehensive review of the literature. Am J Surg Pathol 2004;28:1-30.

4. Chong WH, Molinolo AA, Chen CC, Collins MT. Tumorinduced osteomalacia. Endocr Relat Cancer 2011;18:R5377. 